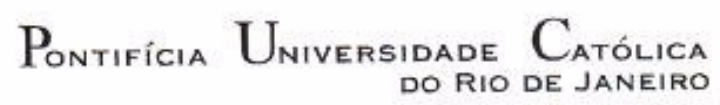

Erwin Pádua Xavier

\title{
CONSTRUÇÃO DO ESTADO, COMUNIDADE POLÍTICA E SEGURANÇA: \\ O caso do Uzbequistão na Ásia Central pós-soviética
}

Dissertação de Mestrado

Dissertação apresentada como requisito parcial para a obtenção do grau de Mestre pelo Programa de Pós-Graduação em Relações Internacionais do Instituto de Relações Internacionais da PUC-Rio.

Orientador: Prof. Dr. Nizar Messari

Rio de Janeiro Julho de 2006 


\title{
CONSTRUÇÃO DO ESTADO, COMUNIDADE POLÍTICA E SEGURANÇA: \\ O caso do Uzbequistão na Ásia Central pós-soviética
}

\begin{abstract}
Dissertação apresentada como requisito parcial para a obtenção do grau de Mestre pelo Programa de PósGraduação em Relações Internacionais do Instituto de Relações Internacionais da PUC-Rio.
\end{abstract}

Prof. Nizar Messari

Orientador

Instituto de Relações Internacionais - PUC-Rio

Prof. Eugênio Paccelli Lazzarotti Diniz Costa Departamento de Relações Internacionais - PUC-Minas

Prof. a Mônica Herz Instituto de Relações Internacionais - PUC-Rio

João Franklin Abelardo Pontes Nogueira Coordenador Setorial do Centro de Ciências Sociais - PUC-Rio 
Todos os direitos reservados. É proibida a reprodução total ou parcial do trabalho sem autorização do autor, do orientador e da universidade.

\section{Erwin Pádua Xavier}

Graduado em Relações Internacionais pela Pontifícia Universidade Católica de Minas Gerais (PUC-Minas) em 2003. Possui interesse acadêmico nas áreas de segurança internacional, resolução de conflitos, teoria de Relações Internacionais, sociologia histórica, o espaço pós-soviético, em especial a Ásia Central.

Ficha catalográfica

Xavier, Erwin Pádua

Construção do Estado, Comunidade Política e Segurança: o caso do Uzbequistão na Ásia Central póssoviética / Erwin Pádua Xavier; orientador: Nizar Messari. Rio de Janeiro : PUC, Instituto de Relações Internacionais, 2006.

217 f.: il. ; $30 \mathrm{~cm}$

Dissertação (mestrado) - Pontifícia Universidade Católica do Rio de Janeiro, Instituto de Relações Internacionais.

Inclui referências bibliográficas.

1. Relações internacionais - Teses. 2. Construção do Estado. 3. Comunidade política. 4. Segurança. 5. Securitização. 6. Sociologia histórica. 7. Construtivismo. 8. Ásia Central. 9. Uzbequistão. 10. Escola de Copenhague. I. Messari, Nizar. II. Pontifícia Universidade Católica do Rio de Janeiro. Instituto de Relações Internacionais. III. Título. 
Aos meus pais, sem cujos amor e apoio essa jornada não teria sido possível. 


\section{Agradecimentos}

Ao meu orientador, Professor Dr. Nizar Messari, pela confiança e paciência, particularmente nos momentos de dificuldade que encontrei pelo caminho.

À CAPES, ao contribuinte brasileiro e à PUC-Rio, pelos auxílios concedidos, sem os quais este trabalho não poderia ter sido realizado.

Aos meus pais, por tudo.

Aos meus grandes e queridos amigos Ana Cristina Araújo Alves, Carolina Moulin Aguiar e Dawisson Lopes, pela amizade incondicional, pela leitura de seções desse trabalho e pelo engajamento construtivo em meus interesses acadêmicos.

Aos meus colegas do IRI, em especial à Ivi Vasconcelos Elias, com quem dividi moradia por um breve período, por transformarem o ambiente do mestrado e alegrarem essa árdua jornada com seu companheirismo e apoio, e pela hospitalidade oferecida a um forasteiro.

Aos meus familiares, por serem uma parte especial do meu mundo.

Aos professores que participaram da Comissão Examinadora, especialmente ao professor Eugenio Diniz.

A todos os professores do IRI, e especialmente à professora Mônica Herz, pelo interesse demonstrado em minha pesquisa e pelas valiosas sugestões que muito contribuíram para o seu aprimoramento. Aos funcionários do IRI, em especial à Maria Helena.

À Vida, por tudo. 


\section{Resumo}

Xavier, Erwin Pádua; Messari, Nizar. Construção do Estado, Comunidade Política e Segurança: o caso do Uzbequistão na Ásia Central pós-soviética. Rio de Janeiro, 2006. 217 p. Dissertação de Mestrado - Instituto de Relações Internacionais, Pontifícia Universidade Católica do Rio Janeiro.

Essa dissertação tem por tema mais amplo o processo de construção das organizações políticas chamadas de Estados. A problemática mais específica sobre a qual ele se debruça, por outro lado, é a da relação entre construção do Estado, comunidade política e segurança, tendo como estudo de caso o processo de construção do Estado uzbeque na Ásia Central pós-soviética. O argumento fundamental do trabalho é o de que cada vez que Estados empreendem atos de securitização - isto é, identificam ameaças existenciais e agem para combatê-las, sejam elas eminentemente internas ou externas - eles estão demarcando os contornos de sua comunidade política ao excluírem certos grupos do vínculo político com o Estado, do que decorre um processo de construção do Estado, ou seja, das instituições políticas estatais. No estudo de caso dos processos de securitização na República do Uzbequistão, exploramos a identificação discursiva e as ações para lidar com a ameaça do neoimperialismo russo, a qual engendrou certos padrões de alinhamentos internacionais e um certo repúdio da herança lingüística e cultural russa internamente, o que resultou na instalação de um processo, mesmo que ainda incipiente, de nacionalização étnica do Estado. Em fins da década de 90, contudo, a percepção dessa ameaça foi sendo suplantada pela identificação da politização do Islã (do Islã político) como a maior ameaça à existência do Estado uzbeque, a qual tem produzido severa repressão a qualquer manifestação religiosa - islâmica, em particular - no país e a oposição de grupos islâmicos radicalizados, em grande medida, por tal repressão. O efeito crucial desse processo foi a construção de um Estado laico, ou seja, de práticas e instituições que não permitem a participação de idéias e representantes religiosos na política.

\section{PALAVRAS-CHAVE:}

1. Construção do Estado, 2. Comunidade Política, 3. Segurança, 4. Securitização, 5. Sociologia Histórica, 6. Construtivismo, 7. Ásia Central, 8. Uzbequistão, 9. Escola de Copenhague. 


\section{Abstract}

Xavier, Erwin Pádua; Messari, Nizar. State-building, Political Community, and Security: the case of Uzbekistan in post-Soviet Central Asia. Rio de Janeiro, 2006. 217 p. Dissertação de Mestrado - Instituto de Relações Internacionais, Pontifícia Universidade Católica do Rio Janeiro.

This thesis tackles the wider theme of the process of construction of those political organizations we call states. The more specific problematique into which it delves, on the other hand, is the relation between state-building, political community, and security, our case study being the state-building process of the Uzbekistani state in post-soviet Central Asia. The fundamental argument in our research is that every time states carry out acts of securitization - that is, identify existential threats and act to counter them, whether these threats be mainly internal or external - they are demarcating the boundaries of their political community by excluding certain groups from the political tie to the state, what brings about a process of state-building, that is, of the construction of state political institutions. In the case study of the processes of securitization in the Republic of Uzbekistan, we explore the identification and actions to counter the threat of Russian neoimperialism, which produced certain patterns of international alignments and a certain denial of the Russian linguistic and cultural heritage internally, which resulted in a process, incipient as it may be, of ethnic nationalization of the state. Toward the end of the 90's, however, such perception of threat was gradually superseded by the identification of the politicization of Islam (of political Islam) as the greatest single threat to the existence of the Uzbekistani state, an identification which has produced severe repression of any religious manifestation - particularly Islamic - in the country and the opposition of groups that were largely radicalized by such repression. The fundamental result of this process was the construction of a lay state, that is, of practices and institutions which do not permit the participation of religious ideas and representatives in politics.

\section{KEYWORDS:}

1. State-building, 2. Political Community, 3. Security, 4. Securitization, 5. Historical Sociology, 6. Constructivism, 7. Central Asia, 8. Uzbekistan, 9. Copenhagen School. 


\section{Sumário}

1. Introdução

2. Construção do Estado, Comunidade Política e Segurança: 22 uma abordagem histórico-sociológica e construtivista

2.1. O Estado Moderno e sua Formação Histórica 23

2.2. Estado, Comunidade Política e Segurança 39

2.2.1. Estado e Comunidade Política 41

2.2.2. Estado, Comunidade Política e Segurança 49

2.3. Construtivismo X Pós-Estruturalismo Sobre Identidades e 64 Ameaças

2.4. Considerações Finais 71

3. A Emergência do Estado Soberano Centro-Asiático: a 74 Ásia Central da Colonização Russa ao Fim da Guerra Fria

3.1. Ásia Central: Delimitações e Características 76

3.2. De Emirados e Khanatos a Províncias do Império Russo 84

3.3. As Bases do Estado Soberano Centro-Asiático São 93 Lançadas: da Revolução de Outubro e a Criação da URSS ao Fim da União Soviética

3.3.1. Da Revolução de Outubro às Demarcações Nacionais das 94 Repúblicas Centro-Asiáticas

3.3.2. Das Demarcações Nacionais Como Processos de Construção Nacional à Era Gorbatchev

3.3.3. Gorbatchev, as Mobilizações Nacionalistas e o Fim da União Soviética

3.4. Considerações Finais

4. Explorando e Problematizando a Construção do Estado Soberano Uzbeque no Pós-Guerra Fria: Securitização, Comunidade Política e as Ameaças do Neoimperialismo 
Russo e do Islã Político

4.1. O Estado Uzbeque e a Herança das Instituições Políticas 123 Soviéticas

4.2. Problematizando a Construção do Estado em Relação à 131 Comunidade Política e a Escola de Copenhague

4.3. A Construção do Estado Uzbeque e a Ameaça do 141 Neoimperialismo Russo

4.4. A Construção do Estado Uzbeque e a Ameaça do Islã 164 Político: uma Profecia Que Se Auto-Cumpre?

4.4.1. O Islã Político ou o Islamismo em Perspectiva 166

4.4.2. Repressão e Radicalização do Islã no Uzbequistão: a 169 Profecia da Securitização se Cumpre

4.5. Considerações Finais 186

5. Conclusão 190

6. Referências Bibliográficas 201

7. Anexos: Mapas 211

7.1. Mapa 1: Ásia Central e Ásia Interior 211

7.2. Mapa 2: Expansão do Império Russo (1533-1894) 212

7.3. Mapa 3: União Soviética 213

7.4. Mapa 4: Regiões do Espaço Pós-Soviético 214

7.5. Mapa 5: Ásia Central e Cáucaso 215

7.6. Mapa 6: Uzbequistão (Político) 216

7.7. Mapa 7: Uzbequistão (Regiões Administrativas) 217 


\section{Lista de Tabelas}

Tabela 1 - Estados Tradicionais x Estados Modernos 